\title{
Mini-Autogenous Skin Grafts with Skin Homografts Versus Autogenous Skin Graft for Covering Post Burn Wounds in Children
}

\author{
EL-SONBATY M.A., M.D.; MOHAMED EL-SHAZLY, M.D.; AWNY ASKLANY, M.D.; \\ MAHMOUD ABD EL-AAL, M.D.; MOHAMED EL-SHERIF, M.D. and MOHAMED SALAH EL-DIN, M.Sc. \\ The Department of Plastic and Reconstructive Surgery, Faculty of Medicine, Assiut University, Egypt
}

\begin{abstract}
Introduction: Burns, as a common type of injury in children, have many developed techniques for management of its wounds, but still have many obstacles which meet plastic surgeons. One of these is the lack of the donor sites for autogenous skin grafting especially in large body surface area burns which are unfortunately common in developing countries with limited technical and financial resources. Finding a suitable methodology to address this problem was our main hypothesis in this project. A mixed grafting technique based on using mini-autogenous skin grafts covered with large homogenous skin graft had been investigated for this purpose.

Patients and Methods: This study is a prospective study of 20 patients with post burn raw areas who were treated as inpatients at the Burn Unit of Assiut University Hospital, Egypt between September 2017 and September 2019. Patients were divided into 2 groups. Group: 1 with 10 children treated by covering the wounds with mini autogenous skin grafts and skin homo grafts and Group: 2 with 10 children treated by the conventional autogenous skin grafts only.
\end{abstract}

Results: The mean age was $6.8 \pm 2.3$ years, 15 males and 5 females. The mean of the harvested skin in group 1 was $1.7 \pm 0.67 \%$ vs. $3.3 \pm 1.06 \%$ for group 2 ( $p<0.001)$. Although the mean time of surgery was significantly longer for patients of group 1, these patients showed significant less bleeding from the site of the donor than the $2^{\text {nd }}$ group. There were non-significant differences between both groups regarding the take of the graft at the recipient site $(p=0.476)$. The hyperpigmentation was significantly higher among patients of group $2(p=0.024)$.

Conclusion: From this study we advocate the use of mini autogenous skin grafts covered with skin homografts for covering the extensive post burn raw areas in children. It provides the covering for wide raw areas in presence of shortage of the donor sites. It is a valid reliable procedure with easier and less expensive aspects suitable for developing and low-income countries where large wound burns are so common.

No specific grants were received by this research from funding agencies in the commercial, public, or not-for-profit sector.

Key Words: Children burn - Extensive raw area - Unavailability of donor site - Inexpensive.

\section{INTRODUCTION}

Burns are common as one of the most catastrophic injury which often shares characteristics of both chronic and acute medical illnesses. Toddlers, preschoolers and infants are the highest risk group for burn injury. These injuries are one of the leading causes of death and hospitalization for children worldwide [1].

El-Sonbaty and El-Otiefy (1991) reported that among 300 patients with burns admitted in Assiut University Hospital Burn Unit, 50.9\% of them were children with the age under 12 years [2].

Burns always meet the criteria for a traumatic event and are this not only disturbing at the time of the burn but often could be a source of ongoing stressful trauma for both the infant and his/her family. The period of the acute stage, burns can be extremely painful and life threatening. Treatment at the early stages includes repeated invasive and painful medical procedures, hospitalization and then followed by frequent visits to the hospital for scar management later. In the late stages, children often face years of reconstructive surgery and rehabilitation and may need to adjust a functional impairment and/or permanent disfigurement [3].

The burn trauma is the most spectacular occurrence, and often the most prominent consequence is extensive injury to the skin. The early covering of post burn raw areas with grafts will influences the further clinical course - also the shock therapy and rapid parenteral fluid, according to formulas which are well known [4].

In the past centuries grafting of skin has evolved to encompass a lot of well-established reconstruction procedures that are uniquely able to restore function, structure, and the cosmetic appearance to a variety of wounds [5]. 
The Hindus was the origin of grafting of skin 3,000 years ago, but until the beginning of the $19^{\text {th }}$ century only reported a few trials. In 1863 Bert's experimental work cleared the way for the pioneers like Reverdin, Wolfe, and Thiersch, to further development of the free skin grafting [6].

Plastic surgeons meet challenges when patients lose more skin than what is feasible to replace by the usual methods of autoplastic free grafting and the surgeon may choose then between two alternatives. He may adopt an expedient such as autoplastic 'pinch grafting' for making one piece of skin do the work of two or three, but the new skin is poor in quality and often unstable. The second alternative is using skin from a relative of the patient or from a voluntary donor, but this type of skin is never permanent [7].

The early investigators made no critical uniqueness between the fate of foreign and original skin, and that skin homografts are routinely used by surgeons to-day without a clear recognition of their fate. Nevertheless, it has come to be acknowledged that foreign skin cannot be used to make the graft permanent in humans, except between monozygotic twins [7]. This homograft is not really rejected by the body during processing because it is rendered immunologically inert, The body instead replaces and remodelsit with an original dermal substitute [8].

Graft survival may be affected with a lot reasons that may interfere with our work so we should be aware that hematoma beneath the graft is the most common reason for skin graft take failure. Similarly, graft adherence to the underlying wound bed may be inhibited by seroma formation so preventing the graft from receiving the necessary nourishment.

Poor recipient site is another common source of failure as the wound have poor vascularity or the surface contamination may have been too great to allow for graft survival, that stimulate release of enzymes and other harmful substances at the wound interface by bacteria and it's inflammatory response which disrupt the fibrin threads adherence of the graft bed [8].

Aim of study: Is to provide an inexpensive expansion value of the autogenous skin graft in shortage of the donor sites in children.

\section{PATIENTS AND METHODS}

This is a prospective study of 20 patients with post burn raw areas who were treated as inpatients at the Burn Unit of Assiut University Hospital,
Egypt between September 2017 and September 2019. Inclusion criteria were age between 3 and 15 years old with burn from 10 to $30 \%$ of total body surface area. The exclusion criteria included children with inhalational, chemical or electrical burns and those with previous or associated other traumas.

Patients in our study were divided into two groups. Group 1, formed of 10 children $(8$ males and 2 females) treated by covering the wounds with mini autogenous skin grafts and skin homo grafts. Group 2, formed of 10 children (7 males and 3 females) treated by the conventional autogenous skin grafts. The demographic data with the post burn wound percentages are shown in Tables $(1,2)$.

Table (1): Showing the demographic data of the two groups.

\begin{tabular}{|c|c|c|c|c|c|}
\hline Group & Age & Sex & $\begin{array}{l}\text { Cause of } \\
\text { the burn }\end{array}$ & $\begin{array}{l}\text { Site of } \\
\text { the burn }\end{array}$ & $\begin{array}{l}\text { Size of } \\
\text { the burn }\end{array}$ \\
\hline Group I & $\begin{array}{l}3 \text { to } 11 \text { year } \\
(7.3 \pm 2.73)\end{array}$ & $\begin{array}{l}\text { Males } 8 \\
\text { Females } 2\end{array}$ & $\begin{array}{l}\text { Scald } 7 \\
\text { Flame } 2 \\
\text { Contact } 1\end{array}$ & $\begin{array}{l}2 \text { on arms } \\
3 \text { on trunk } \\
5 \text { on thighs }\end{array}$ & $\begin{array}{l}\text { From } 10 \% \\
\text { to } 28 \% \\
\text { Mean } \\
(22.9 \pm 5.17)\end{array}$ \\
\hline Group II & $\begin{array}{l}3 \text { to } 12 \text { year } \\
(6.5 \pm 2.75)\end{array}$ & $\begin{array}{l}\text { Males } 7 \\
\text { Females } 3\end{array}$ & $\begin{array}{l}\text { Scald } 8 \\
\text { Flame } 2\end{array}$ & $\begin{array}{l}2 \text { on arms } \\
2 \text { on trunk } \\
6 \text { on thighs }\end{array}$ & $\begin{array}{l}\text { From } 10 \% \\
\text { to } 23 \% \\
\text { Mean } \\
(19.1 \pm 4.38)\end{array}$ \\
\hline
\end{tabular}

Table (2): Showing the percentages of the burn wounds in both groups.

\begin{tabular}{ll}
\hline Group & Percentage of the post burn raw area \\
\hline Group I & From $3 \%$ to $7 \%$ \\
& Mean $(5.3 \pm 1.94)$ \\
Group II & From $3 \%$ to $8 \%$ \\
& Mean $(5.7 \pm 1.57)$ \\
\hline
\end{tabular}

Informed and written consent was taken from their attendants (parents) to be treated as inpatients and to undergo surgical management as well as the donor volunteers and agree to participate in the study after explanation, in accordance to the local ethical committee regulations. Also they are informed that patients will be offered the opportunity to withdraw from the study at any time.

Surgical technique: All patients were given general anesthesia after proper general examination and local wound assessment. All volunteers were given spinal anesthesia for harvesting of the skin homografts.

Regarding patients of Group: 1, harvesting of the skin homo grafts from the relative volunteer 
was usually at the same time of the surgery of the burned child except two patients where the homograft for them were harvested from abdominal dermo-lipectomy skin a day before the surgery after exclusion of any blood transmitted diseases. The skin homografts were meshed manually in 7 patients and by using machinery mesher in the other 3 patients.

For the mini autogenous skin grafts preparation, the following steps had been followed: (a) Harvesting of a small piece of autogenous skin graft using Watson's (skin graft) knife from the limited available donor site (Fig. 1). (b) Preparation of the mini autogenous skin grafts using sterile wooden tongue depressor and knife with blade 24 (Fig. 2 ). (c) The prepared mini autogenous skin grafts were immersed in cold saline in a sterile petri dish (Fig. 3).

After preparation of the post burn raw area by curettage and debridement of any eschar, the wound had been flushed by hydrogen peroxide $10 \%$ to have good hemostasis. The mini grafts are then scattered over the well vascularized raw area (Fig. 4). The manually meshed skin homograft is applied on top of the scattered mini autogenous skin grafts (Fig. 5).

In Group: 2, the conventional technique using split thickness skin grafts for covering post burn raw areas was applied as usual. For both groups dressings were applied with tie-over dressings to prevent any shearing movement. Measuring the total intra operative time including time for harvesting of the homograft from the relative volunteers and measuring bleeding from donor sites was calculated.

Post-operative evaluation: The first dressing for all patients was at the $5^{\text {th }}$ day of surgery to comment on take of the graft, either fully taken, hazy graft take or not taken at all (lost). The graft take percentage in relation to the covered raw area was recorded. The graft donor and recipient complications were reported. The post-operative dressing for all patients of the current study was by a moist exposed burn ointment (MEBO). Postoperative photography was taken for all patients after taking the written consent.

\section{Statistical analysis:}

Statistical package for social science (SPSS) version 20 and Microsoft office 2013 (Excel) were the programs which analyzed data. Parametric data was expressed as mean and standard deviation (SD). The non-parametric data was expressed as number and percentage of the total. Comparing the parametric data was performed using the paired and unpaired $t$-test while comparing the nonparametric data was done using the Chi Square test. $p$-value $>0.05$ is considered non-significant, $p$-value $<0.05$ is considered significant and $p$-value $<0.01$ is considered highly significant.

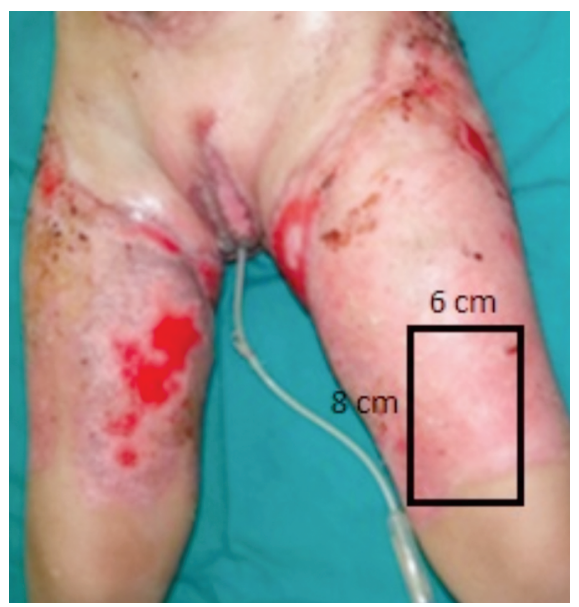

Fig. (1): Showing the previously used donor site and the marking for harvesting a small piece of autogenous skin graft.

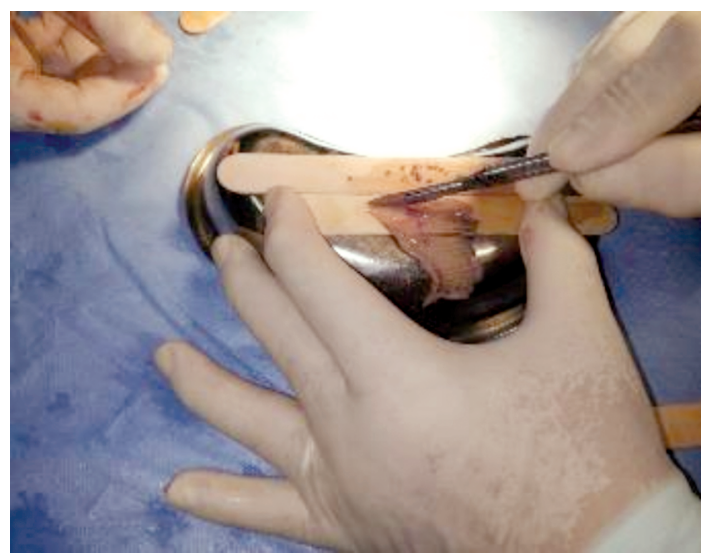

Fig. (2): Showing cutting of the autogenous skin graft over tongue depressor.

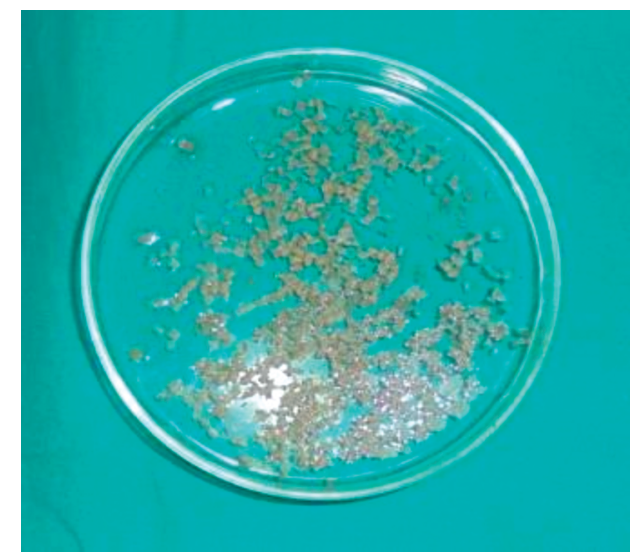

Fig. (3): Glass dish filled with the prepared mini autogenous skin grafts. 


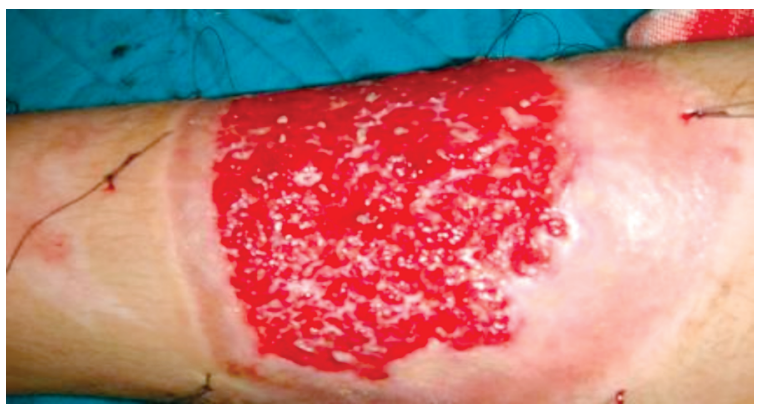

Fig. (4): Scattering of the previously prepared mini autogenous skin grafts over the post burn wounds.

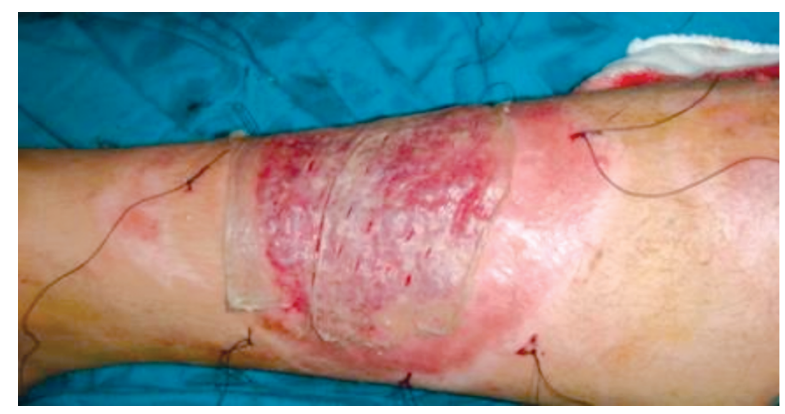

Fig. (5): Manually meshed skin homograft applied on top of scattered mini-autogenous skin grafts on the post burn raw area.

\section{RESULTS}

The mean age in this study was $6.8 \pm 2.3$ years, 15 males and 5 females. The mean percentage of burn raw area was $5.3 \pm 1.94 \%$ for group 1 vs $5.7 \pm 1.57 \%$ for group 2 . The mean percentage of the harvested donor skin in group 1 was $1.7 \pm 0.67 \%$ vs $3.3 \pm 1.06 \%$ for group $2(p<0.001)$ (Table 3 and Fig. 6). Although the mean time of surgery was significantly longer for group 1 patients, they showed significant less bleeding from the donor sites than the second group (Table 3, Figs. 7,8). Graft healing was recorded when there was good take of the graft into the wound with no residual raw areas or haziness of the graft but there was non-significant difference between both groups regarding the take of the graft at the recipient site $(p=0.476)$ (Table 4, Fig. 9).

There was one patient presented by hematoma in group 2 with no recorded similar cases in the first group. There were no seromas among patients of the first group although there were two cases in group 2 which was non-significant. Although the infection rate was higher for patients of the group 1, it did not reach to a significant manner $(p=0.306)$ (Table 5, Fig. 10). The hyperpigmentation was significantly higher among patients of group 2 ( 7 vs 1\%, $p=0.024$ ) (Table 6 and Fig. 11).
The fate of the homograft among group 1 was always loss with good take of the autografts beneath it.

Table (3): Comparison between percentages of burn raw area to intra operative donor percentage in both groups. Presented by Mean \pm SD.

\begin{tabular}{llll}
\hline & Group I & Group II & $p$-value \\
\hline Percentage of burn raw area & $5.3 \pm 1.94$ & $5.7 \pm 1.57$ & \\
Percentage of donor & $1.7 \pm 0.67$ & $3.3 \pm 1.06$ & $<0.001 * *$ \\
Time for operation & $2.23 \pm 0.42$ & $1.36 \pm 0.46$ & \\
Bleeding from donor & $18 \pm 4.22$ & $48 \pm 13.17$ & \\
\hline
\end{tabular}

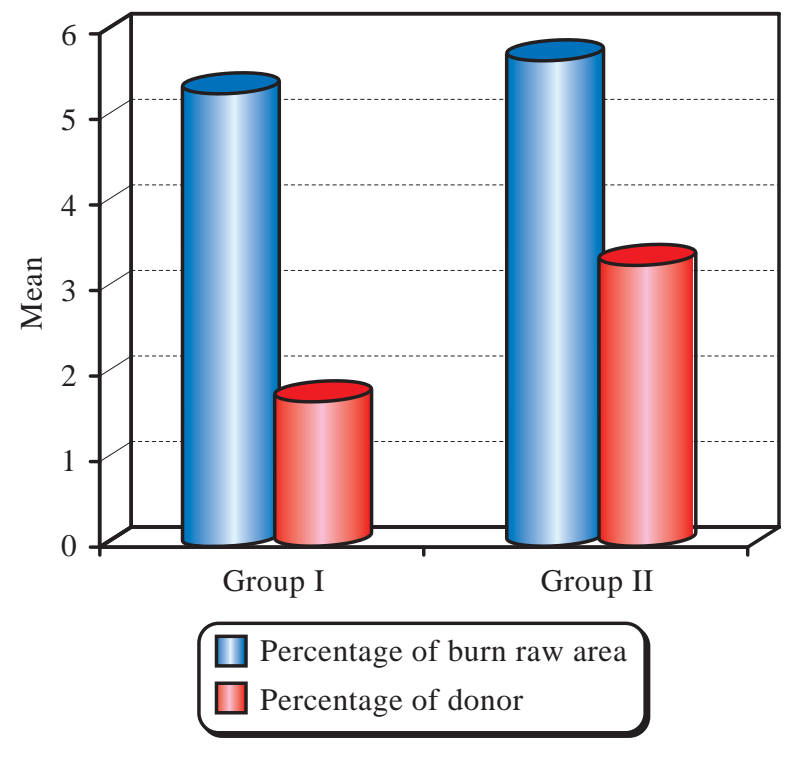

Fig. (6): Difference between both groups in intra operative donor percentage according to the percentage of burn raw area.

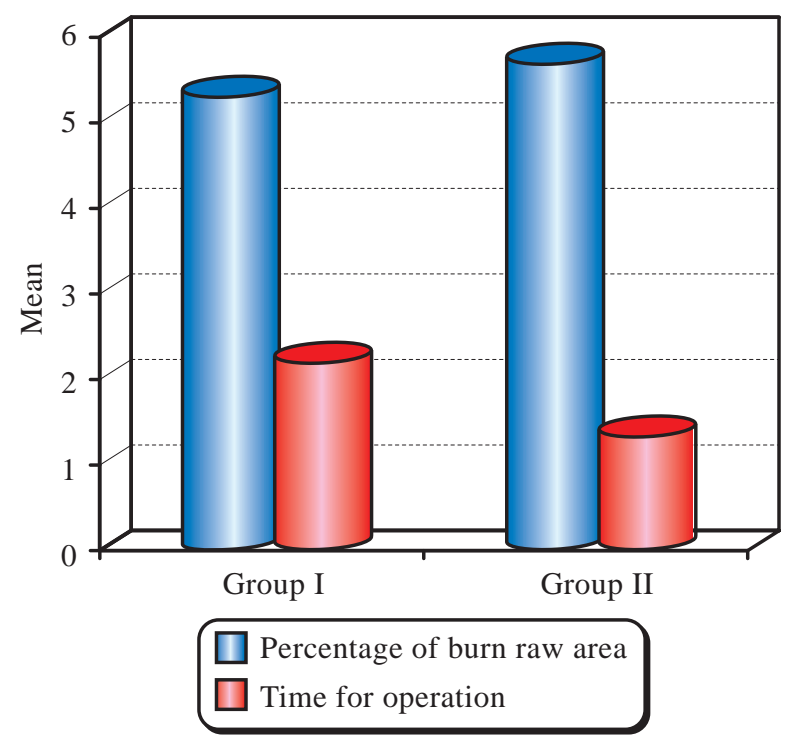

Fig. (7): Difference between both groups in intra operative time for operation according to the percentage of burn raw area. 


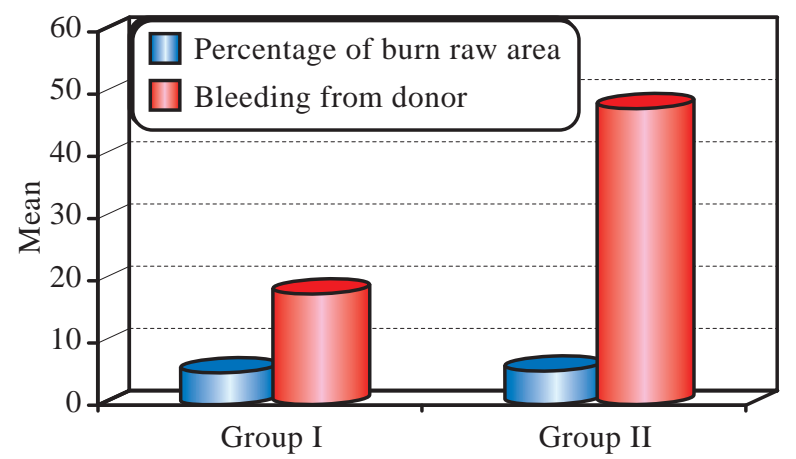

Fig. (8): Difference between both groups in intra operative bleeding from donor during operation according to the percentage of burn raw area.

Table (4): Comparison between take of the grafts in both groups.

\begin{tabular}{lcccccc}
\hline \multirow{2}{*}{ The Graft take } & \multicolumn{2}{c}{ Group I } & & \multicolumn{2}{c}{ Group II } & \multirow{2}{*}{ p-value } \\
\cline { 2 - 3 } & No. & $\%$ & & No. & $\%$ & \\
\hline Taken & 8 & 80 & & 6 & 60 & \\
Hazy then taken & 2 & 20 & & 3 & 30 & 0.476 \\
Hazy then lost & 0 & 00 & & 1 & 10 & \\
\hline
\end{tabular}
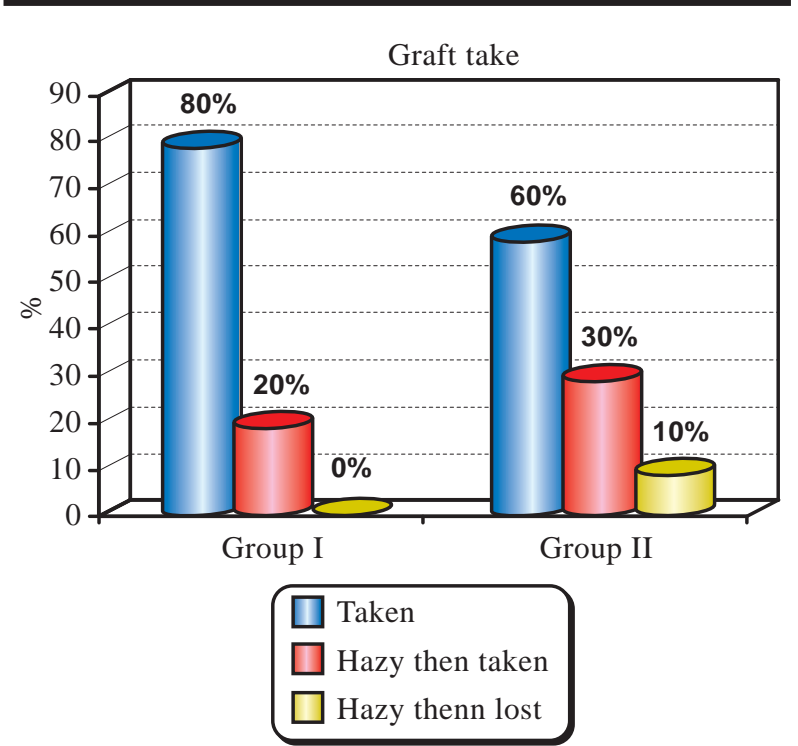

Fig. (9): Differences between take of graft and \% of burn grafted in both groups.

Table (5): Comparison between graft complications in both groups.

\begin{tabular}{lcccccc}
\hline \multirow{2}{*}{$\begin{array}{l}\text { Graft } \\
\text { complications }\end{array}$} & \multicolumn{2}{c}{ Group I } & & \multicolumn{2}{c}{ Group II } & \\
\cline { 2 - 3 } & No. & $\%$ & & No. & $\%$ & \\
\cline { 2 - 3 } & 8 & 80 & & 6 & 60 & \\
\hline Negative & 2 & 20 & & 1 & 10 & \\
Infection & 0 & 00 & & 1 & 10 & 0.306 \\
Hematoma & 0 & 00 & & 2 & 20 & \\
Seroma & & & & & &
\end{tabular}

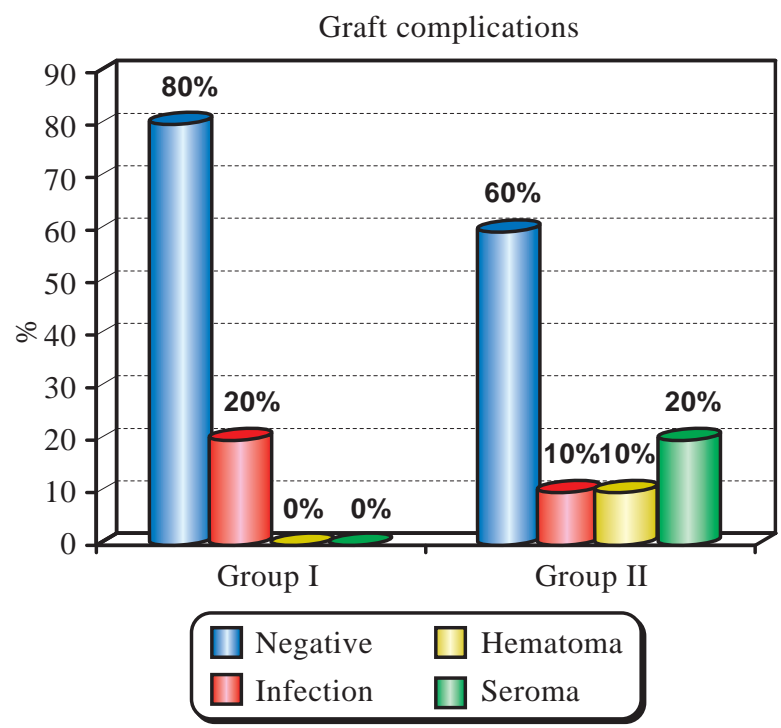

Fig. (10): Differences between graft complications in both groups.

Table (6): Comparison between pigmentation in both groups.

\begin{tabular}{lccccccc}
\hline \multirow{2}{*}{ Pigmentation } & \multicolumn{2}{c}{ Group I } & & \multicolumn{2}{c}{ Group II } & \\
\cline { 2 - 3 } & No. & $\%$ & & No. & $\%$ & p-value \\
\hline Hyperpigmentation & 1 & 1.0 & & 7 & 7.0 & \\
Hypopigmentation & 3 & 3.0 & & 1 & 1.0 & $0.024 *$ \\
Normo-pigmentation & 6 & 6.0 & & 2 & 2.0 & \\
\hline
\end{tabular}
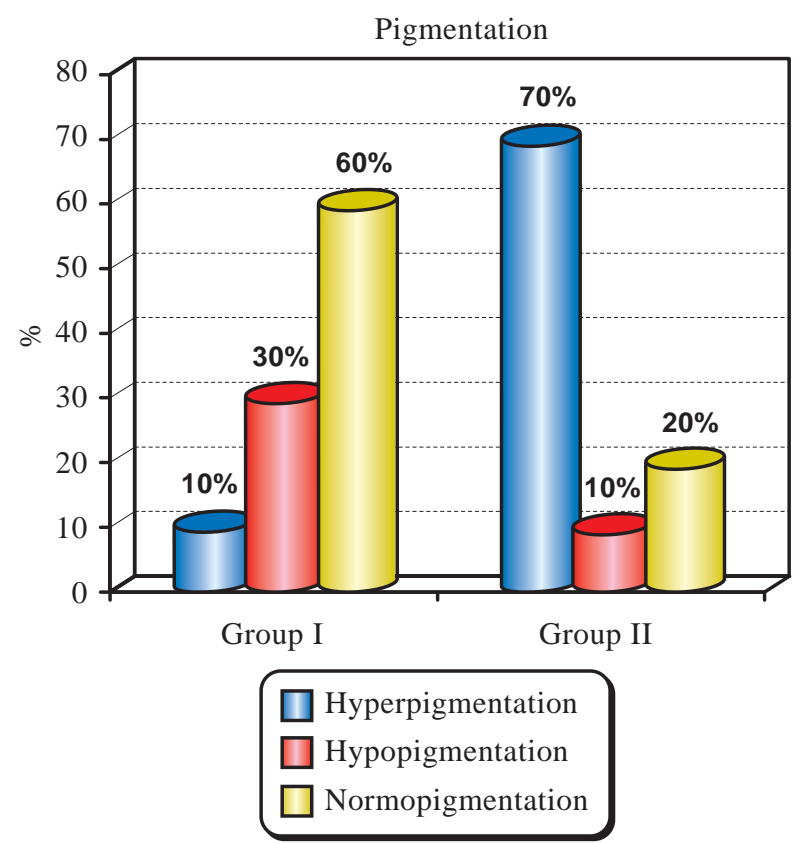

Fig. (11): Differences between pigmentation in both groups. 
Clinical cases:

(B)

(A)
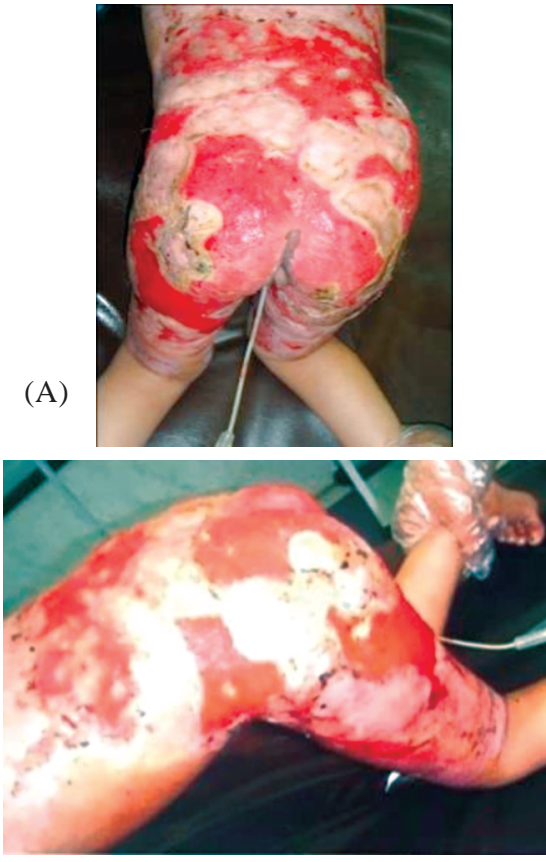

(C)

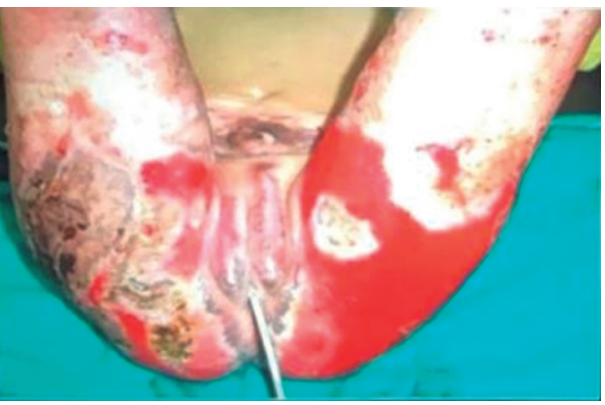

(D)

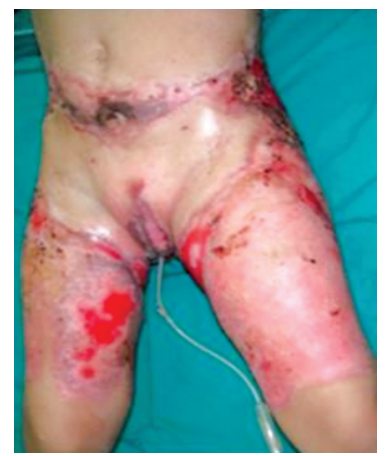

(I)

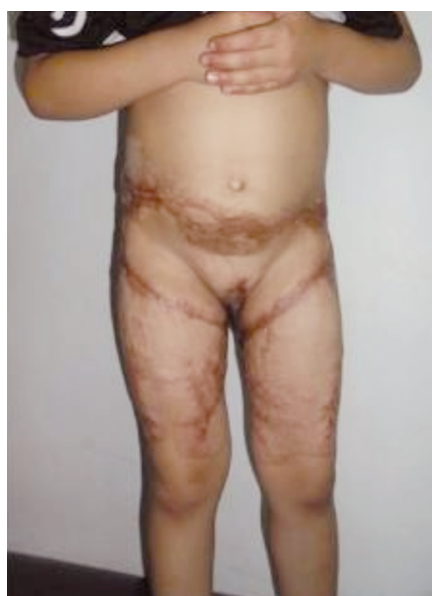

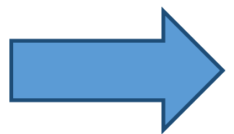

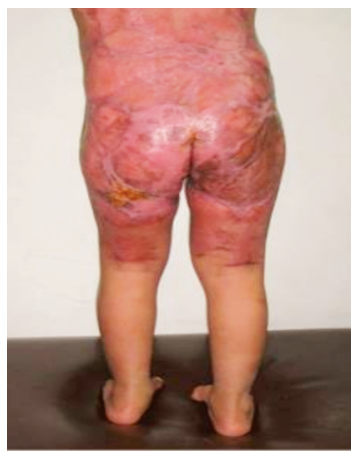

(E)
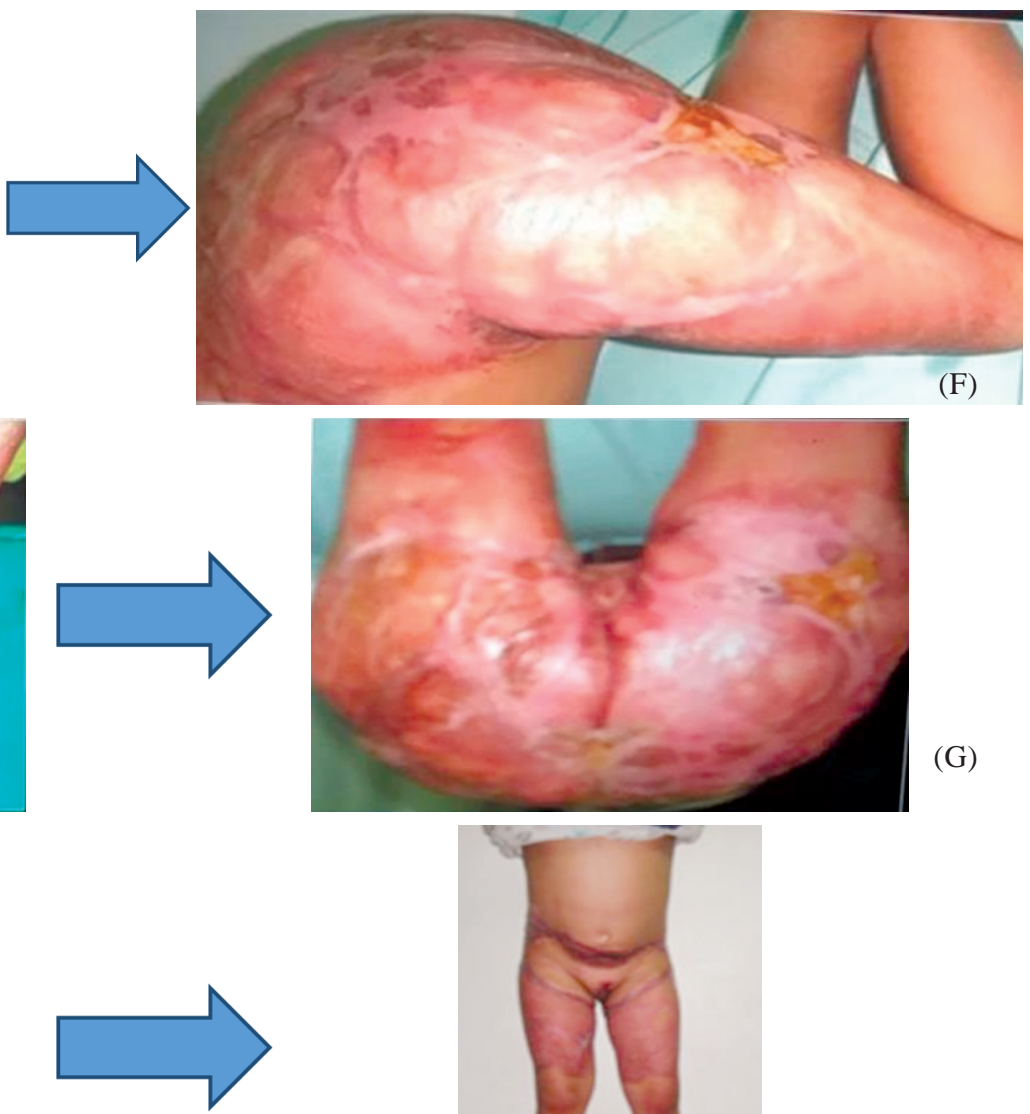

$(\mathrm{G})$

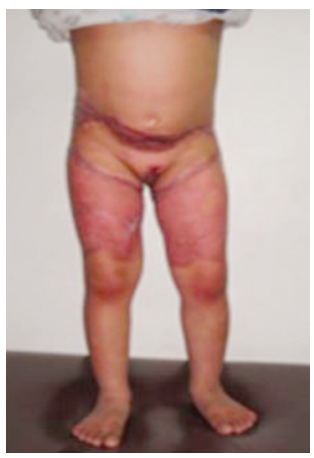

$(\mathrm{H})$

Case No. (1): A four years oldfemale patient in group 1 with post burn raw areas over the back, both buttocks and both thighs which were skin grafted before with the traditional autogenous skin grafts (Figs. 12 a,b,c,d) are showing raw areas over both buttocks, posterior aspect of thighs and trunk while (Figs. 12 e,f,g,h) are showing complete healing of all raw areas 3 months post-operatively. (Fig. 12 i) one year after surgery shows good healing of the donor site and less scaring and sparing abdomen, both thighs and both upper limbs. 
(A)

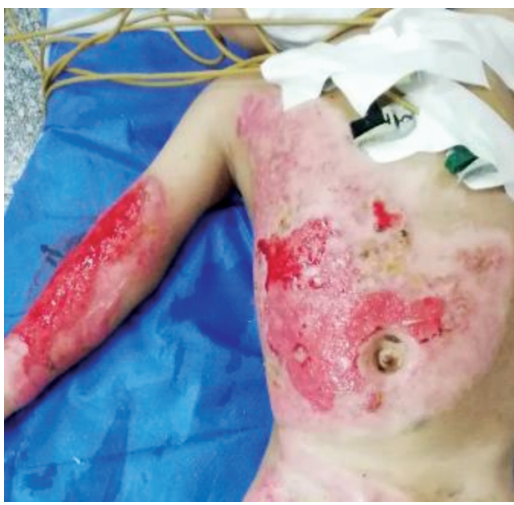

(C)

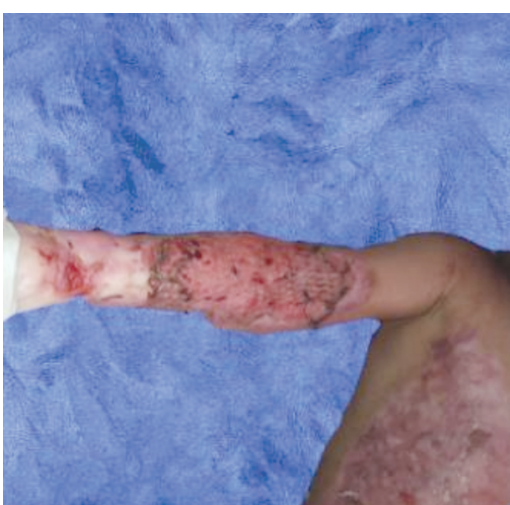

(E)

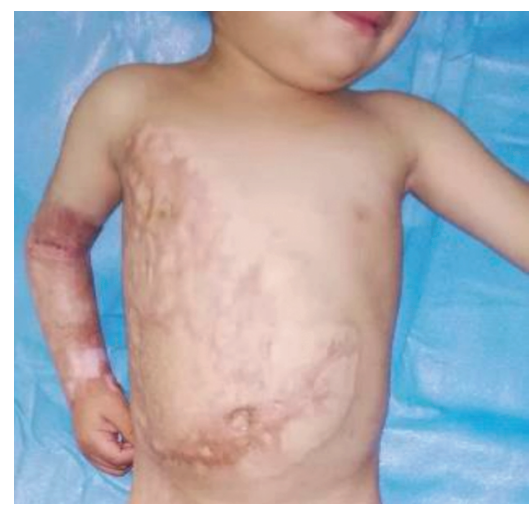

DISCUSSION

Large surface area wounds are unfortunately common in developing countries with limited technical and financial resources. Finding a suitable methodology to address this problem, while saving lives was our main hypothesis in this project. Despite the fact that the outcome of skin grafting over the last decades has significantly improved, the management of severely burned children with $\geq 30 \%$ total body surface area (\% TBSA) burned still represents a challenging task for burn care personnel worldwide [9]. Where there is poor bed vascularity, micrografting can be used with higher success due to low metabolic demand. This is recommended for major burns, $>30 \%$ TBSA, with inadequate donor sites [10].

Loss of skin due to trauma, especially in major burns, requires skin to be grafted to repair the

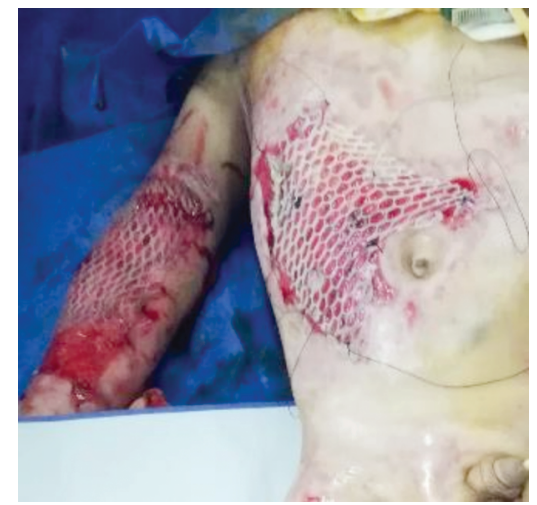

(B)

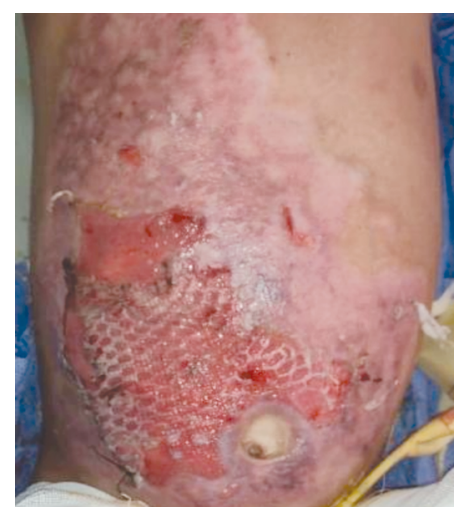

(D)

Case No. (2): A three years old male patient in group 2 with post burn raw areas over anterior trunk and right upper limb which were ready to be grafted Fig. (13 a). Fig. (13 b) shows the condition after applying the meshed autogenous skin grafts, while Fig. $(13 \mathrm{c})$ is showing all grafts taken with healing over the right upper limb 2 weeks post-operatively. Fig. (13 d) demonstrates hazy grafts beginning to lose with signs of epithelialization after 2 weeks over the trunk, while Fig. (13 e) shows scars 3 months after surgery.

tissue loss. For a wide surface area burn, where there is limited donor sites, expansion of these grafts may be needed. moreover, rapid wound closure is a great factor for successful recovery of the patient and can be achieved by good debridement and grafting the raw areas [10].

In the current study mini autogenous skin grafts covered with homogenous skin grafts for covering large post burn raw areas in children were introduced and these results were compared with the conventional autogenous skin graft. This technique is efficient and effective in covering an open wound, particularly with deficiency of the skin graft donor sites.

In 1964 Tanner J et al., published that when the wound which needs to be grafted is large or has convoluted surfaces, partial-thickness skin grafts can be meshed to expand to cover the defect. 
This technique not only increases the surface area which can be covered by the skin graft but also allows the graft to be taken better to a convoluted wound. The disadvantages of this type of grafts are wounds which have a checkerboard appearance, which leaves a less attractive scar, and more contraction of the wound may be a possibility. Another disadvantage is the limited expansion of the graft to the size of the mesher plates [11]. However, the mini autogenous skin grafts aren't limited to any plate size and could be diced, cut and expanded to any size needed. Also the mini-grafts help to reduce the checkerboard appearance of the meshed grafts.

In our work, we noticed the decrease in the percentage of the used donor site in mini autogenous skin grafting in comparison with the percentage of donor sites of the conventional skin grafting. This was resulted in a decrease of the amount of blood loss in relation to the total post burn surface raw areas in group I in comparison with group II, with a consequent decrease in morbidities and mortalities related to the operation.

Although all these benefits in group I, but in comparison with group II there was significant increase in the time of the surgery. There was a time consumed in harvesting homogenous skin grafts from the relative volunteers then meshing them and time consumed in cutting the autogenous skin graft into small pieces then scattering them all over the wound bed. However, the extra time can be reduced by taking the homograft before getting the child into the operation theater or making two teams working together; one for the donor person and the other for the recipient child.

The modified Meek micrografting provides a reliable and versatile method for the coverage of large burn wounds with limited autograft donor sites and is now routinely used in our institution. Its systematic use improves operating times and overall outcomes reducing the number of surgeries, increasing the percentage of graft take, and decreasing the length of stay [12]. But in our case the lake of the technical and financial resources we had to develop a new technique that is reliable and can be used to cover the large post burn wounds that may save the child life, which could be provided by our technique.

Ünal et al., study analyzed; the skin graft loss due to infection at 2005, which was performed on 132 patients who received partial-thickness skin grafts to reconstruct post traumatic raw areas. In all cases, the preoperative evaluation indicated an adequate wound-bed preparation. However, infec- tion leaded to graft loss in 31 patients $(23.5 \%)$ [13]. Our study showed that group I with mixed grafts had $80 \%$ of the cases with no complications while $20 \%$ of the cases were infected. In group II; $60 \%$ of the cases had no complications, $20 \%$ had seromas, $10 \%$ had hematomas and only $10 \%$ of the cases were infected.

Many studies substantiated the claim that moist exposed burn ointments promotes epithelial repair, leads to reduction of water evaporation from burn wound surface, has analgesic effects and provides the optimum physiological environment for healing and improves scar formation [14]. Because of the hyperosmolar medium, these ointments have also been proved to prevent bacterial growth. It is proved that it can change the biological behavior of bacteria, promotes decrease in the bacterial toxicity and invasive capacity, changes the bacterial sensitivity to antibiotics and improves both the local and systemic immunity [15]. In other study the micro skin grafts application combined with MEBO dressing, gauze and elastic bandage in skin defect after burn improved the outcome dramatically [16]. In this study, we have noticed all the above advantages of these ointments as we were able to see epithelialization over the donor site around the fifth day of surgery.

The reconstructive surgeon tackling burn problems must consider the patient's financial, social and occupational needs as well as other factors such as the expected post-burn deformities and also the patient's psychological and motivational status [15]. In this study, we noticed a dramatic decrease in complications related to the use of the combined mini autogenous and homogenous skin grafting as seroma, hematoma or infection. Although the use of homografts which don't permanently take and lost, but it delivers a good future healing bed with the scattered mini autogenous skin grafts. It is a good and cheap substitution for other complex and expensive skin substitutes which may not be readily available in countries with economic hardships.

\section{Conclusion:}

We advocate the use of mini autogenous skin grafts covered with skin homografts for covering the extensive post burn raw areas in children. It provides the covering for wide raw areas in presence of shortage of donor sites. This would also preserve the potential donor sites from arms, legs and abdomen. This technique results in more normal skin coloration in contrast to the hyperpigmentation of the grafted skin in conventional skin grafting methods. Also, it allows an inexpensive expansion 
value of the used mini autogenous skin grafts in absence of a mesher for skin graft expansion or the expensive dermal substitutes. It is an ideal solution for large surface area wounds with limited technical and financial resources.

All authors have approved the final article.

\section{REFERENCES}

1- Pape S.A., Skouras C.A. and Byrne P.O.: An audit of the use of laser Doppler imaging (LDI) in the assessment of burns of intermediate depth. Burns, 27 (3): 233-9, 2001.

2- El Sonbaty M. and El Oteify M.: Epidemiology of burns in Assiut Province, Egypt, during the last two years. Ann. Burns and Fire Disasters, 14: 106-9, 1991.

3- Association A.P.: Diagnostic and statistical manual of mental disorders. BMC Med., 17: 133-7, 2013.

4- Becker D.: Temporary wound dressing of burns with fresh, sterile, frozen porcine skin. Annals of Burns and Fire Disasters, 11: 171-5, 1998.

5- Adams D.C. and Ramsey M.L.: Grafts in dermatologic surgery: review and update on full-and split-thickness skin grafts, free cartilage grafts, and composite grafts. Dermatologic Surgery, 31: 1055-67, 2005.

6- Turnage R.H., Nwariaku F., Murphy J., Schulman C., Wright K. and Yin H.: Mechanisms of pulmonary microvascular dysfunction during severe burn injury. World Journal of Surgery, 26 (7): 848-53, 2002.

7- Gibson T. and Medawar P.B.: The fate of skin homografts in man. Journal of Anatomy, 77 (Pt 4): 299, 1943.

8- Helton W.S., Fisichella P.M., Berger R., Horgan S., Espat N.J. and Abcarian H.: Short-term outcomes with small intestinal submucosa for ventral abdominal hernia. Archives of Surgery, 140 (6): 549-62, 2005.

9- Lumenta D.B., Kamolz L-P. and Frey M.: Adult burn patients with more than $60 \%$ TBSA involved-Meek and other techniques to overcome restricted skin harvest availability the Viennese concept. Journal of Burn Care \& Research, 30 (2): 231-42, 2009.

10- Quintero E.C., Machado J.F.E. and Robles R.A.D.: Meek micrografting history, indications, technique, physiology and experience: A review article. Journal of Wound Care, 27 (Sup 2): S12-S8, 2018.

11- Tanner J., Vandeput J. and Olley J.: The mesh skin graft. Plast. Reconstr. Surg., 34 (3): 287-92, 1964.

12- Medina A., Riegel T., Nystad D. and Tredget E.E.: Modified Meek Micrografting Technique for Wound Coverage in Extensive Burn Injuries. Journal of Burn Care \& Research, 37 (5): 305-13, 2016.

13- Ünal S., Ersoz G., Demirkan F., Arslan E., Tütüncü N. and Sari A.: Analysis of skin-graft loss due to infection: Infection-related graft loss. Annals of Plastic Surgery, 55 (1): 102-6, 2005.

14- Ang E.S., Lee S.T., Gan C.S., See P., Chan Y.H., Ng L.H., et al.: The role of alternative therapy in the management of partial thickness burns of the face-experience with the use of moist exposed burn ointment (MEBO) compared with silver sulphadiazine. Annals of the Academy of Medicine, Singapore, 29 (1): 7-10, 2000.

15- Iovanovich J., Tsati E., Tsoutsos D., Frangia K. and Papalois A.: Moist exposed burn therapy: Evaluation of the epithelial repair process (an experimental model). Ann Burns Fire Disast, 13: 3-9, 2000.

16- Wardhana A. and Samiadji M.J.J.P.R.: Clinical Applications of Micro-Skin Grafting for Skin Defect Coverage, 1 (1), 2012. 